\title{
Essay/Commentary
}

\section{CRITICAL THINKING IN THIS TIME OF GLOBAL PANDEMIC}

\author{
Jove Jim S. Aguas \\ University of Santo Tomas, Philippines
}

This global pandemic is unprecedented; nothing in our recent memory and history has affected our life so drastically and radically. The whole world seems to have stopped - commerce and business, travel and tourism, religious and cultural activities even our social and personal activities have to stand still. Our social and personal life has changed so much that we can no longer just have the normal face to face contact even with people who are close to us; we are literally confined to our homes; work which is so vital to our daily existence has to stop. Economics and commerce has taken a great hit and we are now threading on an unchartered territory. Who knows how things will be after this global pandemic is over? Even our religious and spiritual life has been so affected that now we are attending religious and spiritual activities through the small screen of our smartphones or tablets or the wider screen of our television sets. Gadgets are becoming very essential even for spiritual matters. For the first time in our life we commemorated the Holy Week without congregation and the only way we can participate in the religious activities is through the social media. The sight of Pope Francis at St. Peter's Square all alone during the commemoration of the Holy Week is a very scene. We are now entering a "new normal" and we might as well be get used to it.

In this critical situation brought about by this COVID 19 there are certain things that we need to consider. The first consideration is the disease and the virus that causes it. We need to consider the valuable knowledge about this disease and virus that causes it and the emerging information about the nature of the virus and its potentials. And we need to be fully informed about the nature of the disease and build in our bodies resistance to it and if ever we experience some symptoms of we must take precautionary measures so that we do not spread it.

The second consideration are the pronouncements, measures and protocols being set up by the government both the national and local units. We might have some issues about these measures and protocols but they are set up in order to address this pandemic. How it is done or implemented may be questionable but they are there to provide solution and alleviate our precarious condition.

The third consideration is the information that is being spread around and the news that we are receiving either from main stream media or the social media or even 
in our personal or private social groups. Some of these are genuine and true information and accurate news reporting but some are either fake or half-truth or slanted and biased news reports or simply information meant to misinform and sow confusion and division. Fake news proliferate - new vaccines for the virus, new drugs against the disease - they all give hope, but fake information only give false hopes.

So how do we address or respond to all these things and how do we process all this information while remaining calm and focus on our and our family's safety and well-being and maintain our sanity amidst this global pandemic? There are just many helpful things we can do, but in this essay I will focus on one important thing among the many other things we can do - mindfulness as against thoughtlessness. Mindfulness is keenly related to one of the capabilities that we need to develop in the $21^{\text {st }}$ century critical thinking. In this precarious times and amidst the surge of varying information, data, ideas, opinions, we need to be mindful through the practice of critical thinking.

So, what is thinking? We may ask. Thinking can be considered both as a process and activity. Thinking as a process or activity is something that has a starting point and a progressive sequence that lead to certain ends or results - thoughts - like ideas, theories, principles. The inputs of our thinking are the different data or information, the facts that we gather from our sense perceptions or observations or experiences. These data are then processed by the mind according to certain rules or laws of inference. The end results are certain thought-contents or thoughts in the form of concepts, laws, principles, plans, decisions, strategies, solutions and others. Now thinking as an ability or power is the capacity to generate ideas thoughts, theories, principles, rules and other mental products. Thinking as an immanent ability and activity emanates from within, from within man himself. It emanates from man's mental and rational faculty - from reason or the intellect. Hence, through thinking we generate or produce ideas, principles, theories, laws, formulas, plans of actions, decisions, rules, solutions, etc. Through thinking we are able to relate these thoughts or concepts into more complex mental products, like laws of the land, procedures in sciences, methods of research, strategies in business and economics, and apply these mental products in reality, in life, in society and in the world. And there is no better time to exercise this power of thinking than now.

The highest form of thinking is reasoning. Reasoning has a purpose; thus, we need to take time to state our purpose clearly and distinguish this purpose from related purposes. In deciding on our purpose we need to consider the significant and realistic purposes. Reasoning is an attempt to figure something out, to settle some questions, to solve some problem, to strategize and remedy a certain situation. In figuring out something we need to state clearly the question at issue and express the question in several ways to clarify its meaning and scope. It will be very helpful if we try to identify if a subject matter or question has one right answer, a matter of opinion, or requires reasoning from more than one point of view. We always base our reasoning on certain assumptions. Thus we need to clearly identify assumptions and determine whether they are justifiable. It is important to consider how assumptions are shaping our point of view. This leads us to another thing about reasoning, reasoning is done from some point of view. Therefore, it is important to identify certain points of view and seek other points of view and identify their strengths and weaknesses. Of course, we need 
to be fair in evaluating all points of view. Lastly, reasoning leads somewhere or has implications and consequences. So, it is important that we trace the implications and consequences that follow from our reasoning. We need to search for negative as well as positive implications and always consider possible consequences.

Now let us focus on critical thinking and what it means. First of all, the term "critical" comes from the Greek term "kritikos" which means to question or to analyze. Thus, it could mean inquisitive and analytical thinking, deed or profound thinking; it could mean discerning and intelligent thinking. However, it could also have a negative connotation as faultfinding. flimsy, shrewd and disapproving type of thinking. So while the ability to criticize could be used positively, some have used it destructively in order to tear down the thinking of others. We see a lot of these in this present times to the extent that sometimes we do not want to open our Facebook accounts or read or watch news reports because of the prevalence of such kind of thinking.

Instead of providing a definition of critical thinking something that is quite difficult to do I would rather focus on the "how" or practice of critical thinking. Sometime the "what" is better answered by answering the "how." I will discuss certain basic elements of critical thinking and how we can apply these in this time of global pandemic. So how do we practice critical thinking?

First of all, we must practice correct understanding. Critical thinking involves understanding, which means having a grasp of things, of reality, of issues at hand, of the subject matter and the information available. Correct understanding includes three elements. The first thing is understanding the context. The context is the framework, the setting, the frame of reference, the different connections and relationships within which something must be understood and interpreted. A context maybe social, political, religious, economic, or scientific. An issue or a subject matter therefore, must be understood and interpreted according to its contexts. If we do not understand the framework or connections of issues at hand then we cannot make a full understanding, assessment or evaluation of such issues. Take for example the pronouncements we hear or read about this pandemic, we need to at least understand the context of these pronouncements. The messages we received through our social media accounts have their particular context and therefore we need to understand them within their context. The second is knowing the opposite views, the opinions and ideas of others, the contrary ideas. There are always at least two sides of one and the same coin, and there are always opposing views on every subject matter like the issue about what the government is doing to fight this global pandemic. Every day we are bombarded with opposing comments and opinions about certain pronouncement or measures implemented by the government and of course most of the time we do not like the opinion that is against our personal stand, but it helps us have a more balanced view. To think critically is to know the opposing views, and once we understand the opposing views, we are in a better position to compare, to respond, to analyze rightly and correctly. The third is understanding the whole subject matter, the wide ranging issues. We must have a comprehensive understanding of the whole range of ideas, opinions, views involved in the discussion of this global pandemic. This global pandemic is so complex so we need to have a more or less comprehensive 
understanding of it and its related issues and we have plenty of time to do that in this time of enhanced community quarantine. Of course we cannot always have a full understanding of all these matters but we can at least make a good effort at it.

The second element is thinking for our self. To think critically is to use our own power or ability to think or use our reason in discerning or evaluating an issue or topic. We must have our own personal assessment and evaluation of the issues at hand and the surrounding information. We cannot allow others to think for us or to simply follow what others think and adopt their own ideas and thoughts or simply comply with their wishes without the benefit of a personal reflection. In this time of crisis, we cannot just agree and blindly follow the dictates of others. Again, the main stream and social media exert a lot of influences on our thinking, but while we listen to them, we need to have our independent view. We need to be conscious that fake news and misinformation abound. Of course, it does not mean that we will always end up with a different view because we can also accept the views of others, but at least, we have accepted and validated them with our own thinking and reason.

Third is we need to practice proactive thinking. Proactive thinking means utilizing our intelligence, knowledge and abilities in order to deal with different situations and issues. It means getting involved in useful and meaningful endeavors and tasks instead or remaining passive and indifferent. In this time of global pandemic and crisis we need to take initiatives and make decisions on our own instead of waiting passively to be told of what to do or think. The worst is to rant and complain without doing anything concrete and helpful to address the present crisis. While the government is crafting solutions to our present problems we also need to do our own share. We need to commit ourselves to participate is civic actions so we can face the challenges of this pandemic. Of course we can always criticize the government and to a greater extent the criticisms against the government have also resulted into a lot of positive things. But we need to engage in meaningful discussions and collaborative actions so we can win this fight against this disease.

Fourth is we need to maintain an open mind. Openness of mind means being open to the ideas and opinions of others. One does not have the monopoly of ideas much less of good ideas. There are good ideas and thoughts we can learn from others, from other sources, from our new experiences and encounters with other people. There are a lot of experts in different fields who can contribute their knowledge and expertise to find or craft solutions to this enormous problem we are now facing. The government for example can tap these experts because this is a battle that involves everyone. The problem sometimes is that some people tend to cling to their ideas and views tenaciously that they can no longer see, learn and accept new ideas. To be a critical thinker we need to be open to new views, new interpretations, new concepts. Of course this does not mean accepting outright the new ideas or concepts presented to us, it simply means that we welcome them as another interpretation or view, a probable source of new knowledge which can probably be integrated into our own knowledge. The most viable solution to any problem especially the problem of a global proportion is a solution that considers the areas of knowledge, natural and social sciences, medicine and allied sciences, commerce and finance, humanities and philosophy, etc. 
The fifth is considering different avenues to the truth. When we open our minds to new or other ideas we open ourselves to different avenues to the truth; different possibilities, different perspectives. It is like opening new windows through which we can see new things or probably the same things but in a new perspective and light. We can probably see a different solution to the problem we are facing right now if we are willing to listen and examine carefully the views of others. Our beliefs or opinions represent only one view or perspective, there are definitely other viewpoints that are equally important or helpful that need to be taken into consideration in order to have a more complete understanding of our problem and ultimately find a suitable solution.

Next which I consider to be very important is we need to practice constructive questioning and challenging certain beliefs or opinions. Sometimes people entertain the negative interpretation of the act of questioning because questioning is sometimes used as outright opposition or a radical opposition to the views of others without any basis or reason. Constructive questioning is done in order to clarify or confirm a particular opinion or idea which has been expressed. It means going back to the real issue or the original interpretation, and clarifying whether such interpretation or ideas or opinion are indeed right and correct. Sometimes there are pronouncements by the government that need to be further clarified and it is just reasonable to ask questions. The government cannot take this questions negatively because most of them are asked with good intentions. Of course nowadays, it is quite difficult to determine the intention of people when they ask questions, but it is a reason to consider their questions. However, the critical thinking does not stop with a constructive questioning, the critical thinker must challenge idea or belief, theory or practice if it is discovered or established after constructive questioning that such idea or belief, theory or practice is not correct or feasible or applicable. The critical thinker is duty bound to oppose it, to challenge it as to its correctness, truth, value and practicality. There are certain questionable pronouncements and measures made by the government and good enough certain sectors have questioned and challenge them. This process filters the ideas and practices and in our present condition the questions and challenges in the form of criticisms from responsible media and private individuals have actually enhanced and improve the way we handle things now.

Finally, critical thinking is thinking together with others. This is related to having an open mind and considering the opinions and views of others. A critical thinker is a team-thinker. One cannot be confined to his own ideas and thoughts; the critical thinker shares his ideas and acts together with others. The ultimate purpose is to come up with the best idea or at least the better idea. In this time of great crisis, we need to think together as one. We need to collaborate and participate in finding a suitable solution to our problems.

To summarize, critical thinking as an active, purposeful, clear and organized and self-initiated rational process, ultimately results to the following:

1) a proper understanding of things and issues - like the global pandemic caused by COVID 19 and the virus that causes it, the pronouncements and measures 
of the government relative to this global pandemic and the many information and news that we received, hear and read every day,

2) conceive and formulate clear ideas and concepts - like crafting workable or feasible solutions to our problems, adjusting our life and activities to the "new normal" scheme of things,

3) make true and accurate judgments and decisions - like in dealing with news and information both fake and genuine,

4) arrive at valid arguments, acceptable justification and sound reason - like in engaging in meaningful conversations and discussions about this crisis,

5) achieve our goals and purposes - like winning this fight against this disease and surviving this global pandemic.

By being mindful through critical thinking we also achieve freedom and liberation from ignorance, blind adherence and thoughtless conformism. Of course the practice of critical thinking is not enough because thinking will not result to something concrete if we do not act. Critical thinking translated into wise action is prudence. Prudence is doing the right thing is the proper manner, in the right time and right place. Hence, if we think critically as one and act prudently as one, then we will heal as one. 